\title{
Studies on Ciliary Dyskinesia Factor in Cystic Fibrosis. III. Skin Fibroblasts and Cultured Amniotic Fluid Cells
}

\author{
Nigholas G. Beratis, ${ }^{27]}$ James H. Conover, Elaine J. Conod, Richard J. Bonforte, \\ AND Kurt HirschHorN
}

Department of Pediatrics, Division of Medical Genetics, Mount Sinai School of Medicine of the City University of New York, New York, New York, USA

\section{Extract}

The cell-free media from cultured skin fibroblasts derived from 16 healthy subjects, 13 homozygotes, 6 obligate heterozygotes, and 1 potential heterozygote for cystic fibrosis (CF) were investigated for ciliary dyskinesia factor (CDF) by a modified rabbit tracheal bioassay. Fluid was obtained for study from cultures during growth phase, 24 and $48 \mathrm{hr}$ after feeding, before confluence had been reached. A positive CDF response was demonstrated in the media of all homozygous and heterozygous for CF skin fibroblast cultures, after incubation of the culture fluid with human immunoglobulin $G$ (IgG). No CDF response was observed before the addition of IgG. Although there was a tendency of the cell-free media obtained from the CF homozygous fibroblast cultures to elicit a stronger CDF response than the media from heterozygous cultures, no consistent distinction between homozygous and heterozygous fibroblast cultures could be obtained. The fluid of 15 out of 16 fibroblast cultures derived from normal donors did not demonstrate CDF activity before or after the addition of IgG. The media from cultured amniotic fluid cells obtained from a pregnant woman homozygous for $\mathrm{CF}$ and from four pregnancies derived from heterozygous parents demonstrated CDF activity in the presence of $\mathrm{IgG}$. The media of 10 out of 11 control amniotic fluid cell cultures were $\mathrm{CDF}$ negative. In the one CDF-positive control culture a positive CDF response was also elicited in the maternal serum. Media from CF fibroblast cultures, to which IgG had been added, lost their CDF activity after treatment with anti-IgG. The culture fluid from confluent fibroblast and amniotic fluid cell cultures of all types of subjects, including control subjects, inhibited the ciliary activity of rabbit tracheal explants without addition of IgG. No CDF activity was observed in the amniotic fluid of a fetus affected with CF. Amicon filtration experiments demonstrated that a molecule with molecular weight between 1,000 and 10,000 produced by CF fibroblast cultures causes ciliary dyskinesia in the presence of IgG. The findings suggest that cultured skin fibroblasts and amniotic fluid cells that carry the $\mathrm{CF}$ gene in a homozygous or heterozygous state produce a small molecule, preciliary dyskinesia factor (pre$\mathrm{CDF}$ ), which is activated in the presence of $\operatorname{IgG}$, as tested with the rabbit bioassay. It appears that this activation of pre-CDF could be reversed by its removal from the IgG.

\section{Speculation}

Cells from all individuals produce a pre-CDF, which is a normal product important for rapid changes in electrolyte flux at the cell membrane. This molecule is normally 
rapidly inactivated by an appropriate enzyme. The genetic defect in CF is in the reduced activity of this enzyme, which results in abnormalities at the cell membrane because of excess of pre-CDF, and, after activation of pre-CDF to CDF by IgG, in interference with bronchial ciliary function.

\section{Introduction}

The finding by Danes and Bearn that cultured skin fibroblasts in most homozygotes and heterozygotes for CF show metachromasia $[5,6]$ suggested that the $C F$ gene affects somatic cells and that the CF genotype may be expressed on the tissue culture level. Shortly thereafter, an increased accumulation of acid mucopolysaccharides was observed in skin fibroblasts from CF patients [11]. Subsequently it was reported by Bartman et al. [1] that cultured skin fibroblasts from patients with CF have an increase in the size and number of lysosomes in parallel with an increase of the amount of the material stored within them. Increased intracellular glycogen [12] and decreased collagen synthesis and collagenolysis [8] have also been described. In spite of the indications that CF may be a lysosomal disorder, several lysosomal hydrolases tested in cultured skin fibroblasts have demonstrated normal enzymatic activity $[9,15]$.

At the present time the primary metabolic defect in CF remains unknown. A deficiency of trypsin-like activity in the saliva [13] and kallikrein activity in the plasma [14] of patients with CF has been described, but no significant abnormality has been detected in the bradykinin system of CF patients [10].

Recently Danes and Bearn [7] demonstrated inhibition of the ciliary activity of oyster gill tissues by using the cell-free medium of cultured skin fibroblasts from metachromasia-positive homozygotes and heterozygotes for $\mathrm{CF}$. We have previously detected the presence of a $\mathrm{CDF}$ in the cell-free media of short term peripheral leukocyte cultures and long term lymphoid cell lines derived from both homozygotes and heterozygotes for CF [3]. Bowman et al. [2], by using DEAE-cellulose chromatography iclentified, in media from fibroblast cultures derived from patients with GF, a chromatographic fraction that inhibits the ciliary activity of oyster gill tissues. Gel filtration of the fraction which contained the ciliary inhibitor separated three protein peaks which corresponded to molecular weights of $140,000-160,000,20,000$, and 13,000 or less, but ciliary inhibitory activity could not be detected in any of these molecular weight species.

The present study describes the production of pre-
CDF by cultured skin fibroblasts and cultured amniotic fluid cells derived from individuals which carry the CF gene in a homozygous or a heterozygous state.

\section{Materials and Methods}

\section{Skin Fibroblasts, Amniotic Fluid, and Amniotic Fluid Cells}

Skin fibroblast cultures were derived from $13 \mathrm{pa}$ tients with CF, 6 obligate, and I potential heterozygote for CF [17], and 16 normal control subjects. The fibroblasts were cultivated in Roswell Park Memorial Institute (RPMI) 1640 medium supplemented with 20\% fetal calf serum, $1 \% 200 \mathrm{~mm}$ L-glutamine, penicillin, and streptomycin [18].

Amniotic fluid was obtained by transabdominal amniocentesis between the 15th and 19th week of gestational age. One amniotic fluid $(A F-1)$ was derived from one amniotic sac of a nonidentical twin pregnancy of a 23-year-old CF homozygous mother [19]. Cord sera and cultured cells derived from pieces of both amniotic membranes of this pair of twins who were therapeutically aborted due to respiratory distress in the mother, were also studied. Three other amniotic fluids $(A F-2$ [20], $A F-3, A F-4[21])$ were obtained from pregnancies which resulted from the mating of obligate heterozygotes for CF. In a fifth case $(A F-5)$ the husband was an obligate heterozygote for $\mathrm{CF}$ and his pregnant wife demonstrated a positive CDF response in both her serum and the culture medium of phytohemagglutinin-stimulated short term peripheral leukocyte cultures, a state consistent with heterozygocity $[3,4]$. The sera of five pregnant women with a negative family history for CF were also tested for CDF activity. Serum from clotted cord blood, obtained after the delivery of the fetuses from whom $A F-2$ and $A F-4$ were derived were studied for CDF effect. Sweat tests performed on the products of the pregnancies from whom $A F-2$ and $A F-4$ were obtained were normal. The fetuses of $A F-3$ and $A F-5$ have not yet been delivered. Eleven amniotic fluid cell cultures obtained from women at risk for a chromosomally abnormal child, and found to carry a normal fetus, were used as control subjects in the study. Amniotic fluid cells were cultured in RPMI 1640 medium 
supplemented with $30 \%$ fetal calf serum, L-glutamine, and antibiotics. Cultures were maintained in $25 \mathrm{~cm}^{2}$ plastic flasks [22], at $37^{\circ}$, in $5 \mathrm{CO}_{2} \%$ in air. Before the study, skin fibroblasts and amniotic fluid cells while still in growth phase, were subcultivated by trypsinization with $0.25 \%$ trypsin [18] and cultures were refed with $5 \mathrm{ml}$ medium $24 \mathrm{hr}$ later. The culture medium was removed after $48 \mathrm{hr}$, before the cells had reached a confluent state (approximately $50-80$ cells/optic field, magnification 100 times) and centrifuged at $200 \times g$ for $10 \mathrm{~min}$. The supernatant cell-free medium was tested for CDF activity by the rabbit tracheal bioassay. In certain cases the medium was removed for study after a 24-hr culture. No attempt was made to study the skin fibroblasts for metachromasia. Skin fibroblasts and AF cells used in the study were healthy, actively proliferating cells between the 2nd and 10th passage and maintained in culture for less than 3 months.

The amniotic fluid from a pregnancy, which resulted in an affected child with CF (the cells, obtained at 22 weeks of pregnancy, failed to grow in culture) was also tested for CDF activity.

\section{Bioassay}

The cell-free medium of each culture was assessed for cilio-inhibitory properties by a modification [4] of the Spock bioassay system [16] which utilizes ciliated rabbit tracheal explants. The culture media were coded and studied blindly by two observers. Each sample was assayed at least twice and in several instances multiple samples prepared from the same fibroblast strain were studied. The ciliary reaction was observed and recorded at 3 and $6 \mathrm{~min}$. The cilio-inhibitory properties of the culture media were studied originally without the addition of IgG. Subsequently, the same media were tested after the addition of $100 \mu \mathrm{g} / \mathrm{ml}$ human $\operatorname{IgG}$ [23] and incubation at $37^{\circ}$ for $15 \mathrm{~min}$. Cell-free media obtained from CF homozygous skin fibroblast cultures were incubated with $\mathrm{IgG}$, as above, and subsequently $0.9 \mathrm{ml}$ media was mixed with $0.1 \mathrm{ml}$ rabbit antiserum to human $\mathrm{IgG}$ (concentration of stock solution $4.9 \mathrm{mg} / \mathrm{ml}$ ) [23]. The mixture was incubated at $37^{\circ}$ for $1 \mathrm{hr}$ and subsequently overnight at $4^{\circ}$. Thereafter, the medium was centrifuged and the supernatant was assayed for the presence of cilioinhibitory activity.

\section{Amicon Filtration of Culture Media}

Cell-free media from $\mathrm{CF}$ skin fibroblast cultures were filtered through UM10 Amicon filters [24] at $4^{\circ}$.
The nitrogen pressure applied for the filtration was 50 psi. Part of the filtrate was tested for CDF activity before and after the addition of IgG and the remainder was filtered through a UM2 Amicon filter. The UM2 filtrate was also tested for CDF effect. The retentates of the UM10 and UM2 filters were resuspended three times in RPMI 1640 medium and were refiltered each time through the same filters. The washed retentates were suspended in the same volume of medium originally used for filtration through each filter and assayed for cilioinhibitory activity with and without IgG.

To $2.8 \mathrm{ml}$ medium of a skin fibroblast culture derived from a patient with CF was added $0.5 \mathrm{ml}$ containing $500 \mu \mathrm{g}$ human $\operatorname{IgG}$ and the mixture was incubated at $37^{\circ}$ for $90 \mathrm{~min}$. This mixture, after being tested for CDF activity, was filtered through a UM10 Amicon filter and the CDF activity of the filtrate was studied before and after the addition of $\operatorname{IgG}$. The retentate was reconstituted to the original volume of $3.3 \mathrm{ml}$ with fresh medium and was also tested for CDF activity. CDF-positive culture media from long term lymphoid lines derived from patients with $\mathrm{CF}$ were filtered through UM10 filters and the filtrate was tested for CDF activity before and after the addition of IgG. The retentate was also tested for CDF effect after being reconstituted to the original volume.

Cell-free media from confluent skin fibroblast cultures derived from normal and $\mathrm{CF}$ donors were evaluated for CDF activity without $\operatorname{IgG}$ and thereafter were subjected to filtration through UM10 filters. The filtrates were also studied for CDF effect without addition of $\operatorname{IgG}$.

\section{Results}

\section{Cultured Skin Fibroblasts}

All studies were performed on media from cells in growth phase unless otherwise stated. Table I presents the findings of the bioassays performed on the cell-free media of cultured skin fibroblasts. Fifteen out of 16 skin fibroblast cultures derived from normal donors did not demonstrate CDF activity before or after the addition of $\operatorname{IgG}$ in the culture medium. In one culture obtained from an apparently normal infant a positive CDF effect was elicited from multiple preparations obtained from various culture flasks. When the serum of the donor of the skin fibroblasts and the sera from both of his parents were studied, a positive CDF response was also observed. A sweat test performed in 
the 6 th month of life demonstrated a normal chloride concentration. The cell-free media obtained from fibroblast cultures from 13 CF homozygotes, 6 obligate heterozygotes, and 1 potential heterozygote demonstrated CDF activity when human IgG was added to the culture medium. The same media were CDF negative before the addition of IgG. The media of $12 \mathrm{CF}$ homozygous skin fibroblast cultures demonstrated a strongly positive CDF response at $6 \mathrm{~min}$ and only 1 elicited a weak positive CDF effect at the same time. Of 6 obligate heterozygous for $\mathrm{CF}$ cultures studied, 3 demonstrated strongly positive CDF activity and the remaining 3 elicited a weakly positive CDF response.

Media from fibroblast cultures homozygous for CF, which were $\mathrm{CDF}$ positive after the addition of $\mathrm{IgG}$ and were subsequently treated with rabbit antiserum to human $\operatorname{Ig} G$, became CDF negative (in the 6-min bioassay).

The cell-free media from confluent skin fibroblast cultures derived from normal subjects, heterozygotes, and homozygotes from CF always caused ciliary dyskinesia before $\operatorname{Ig} \mathrm{G}$ was added.

\section{Amniotic Fluid and Cultured Amniotic Fluid Cells}

Table II lists the results of the bioassays carried out on the media of cultured amniotic fluid cells. The cell-free media from 10 out of 11 control amniotic fluid cell cultures did not produce detectable CDF before or after the addition of $\operatorname{IgG}$. However, the culture medium from one control culture elicited a positive $\mathrm{CDF}$ effect at 6 min, when IgG was added to the medium. The maternal serum of this case was found to be $\mathrm{CDF}$ positive, whereas the paternal serum was $\mathrm{CDF}$ negative. The culture medium from $A F-1$, that was obtained from a pregnant woman affected with $\mathrm{CF}$, in the presence of $\operatorname{IgG}$ produced a weakly positive $\mathrm{CDF}$ response at $3 \mathrm{~min}$, which developed into a strongly positive $\mathrm{CDF}$ response at $6 \mathrm{~min}$. Similarly, the media from $A F-2, A F-3$, and $A F-4$ (both parents are obligate heterozygotes for CF) elicited a weakly positive CDF response at $3 \mathrm{~min}$ and showed a strongly positive $\mathrm{CDF}$ effect at $6 \mathrm{~min}$, when $\operatorname{IgG}$ was present in the medium. CDF activity was also detected in the medium from $A F-5$ (husband obligate heterozygote and wife probably heterozygote for $\mathrm{CF}$ ) after the addition of IgG. $A F-1, A F-2, A F-3, A F-4$, and $A F-5$, when studied during growth phase, were CDF negative before the addition of IgG. The media from the cultured amnion cells with IgG and the cord sera derived from the pair of aborted twins of a CF-affected mother elicited a
Table I. Ciliary dyskinesia factor (CDF) activity in cell-free media from skin fibroblast cultures derived from homozygotes and heterozygotes for cystic fibrosis and normal control subjects ${ }^{1}$

\begin{tabular}{|c|c|c|c|}
\hline \multirow{2}{*}{ Subjects studied (no.) } & \multirow{2}{*}{ No. } & \multicolumn{2}{|c|}{ Ciliary reaction at $6 \mathrm{~min}$} \\
\hline & & Without IgG & With $\mathrm{IgG}^{2}$ \\
\hline \multirow[t]{2}{*}{ Control subjects (16) } & 15 & - & - \\
\hline & $1^{3}$ & - & ++ \\
\hline \multirow[t]{2}{*}{ CF-Hom. (13) } & 12 & - & ++ \\
\hline & 1 & - & + \\
\hline \multirow[t]{2}{*}{$\mathrm{CF}-\mathrm{OH}(6)$} & 3 & - & ++ \\
\hline & 3 & - & + \\
\hline CF-PH (1) & $1^{4}$ & - & + \\
\hline
\end{tabular}

${ }_{1}$ CF-Hom.: homozygote for cystic fibrosis; CF-OH : obligate heterozygote for cystic fibrosis; CF-PH : potential heterozygote for cystic fibrosis; - : no dyskinesia ; + : weak dyskinesia ++ : strong dyskinesia.

${ }^{2}$ Human $\mathrm{IgG}, 100 \mu \mathrm{g} / \mathrm{ml}$ of medium.

${ }^{3}$ Serum of this case and both paternal and maternal sera were CDF positive; a sweat test was negative.

${ }^{4}$ Serum demonstrated CDF activity.

Table II. Ciliary dyskinesia factor (CDF) activity in media from cultured amniotic fluid cells ${ }^{1}$

\begin{tabular}{cccc}
\hline \multirow{2}{*}{ Cases studied (no.) } & co. & \multicolumn{2}{c}{ Ciliary reaction at $6 \mathrm{~min}$} \\
\cline { 3 - 4 } & & \multicolumn{2}{c}{ Without IgG $\mathrm{With} \mathrm{IgG}^{2}$} \\
\hline Control subjects (11) & 10 & - & - \\
& $1^{2}$ & - & ++ \\
$A F-1^{3}$ & 1 & - & ++ \\
$A F-2^{4}$ & 1 & - & ++ \\
$A F-3^{4}$ & 1 & - & ++ \\
$A F-4^{4}$ & 1 & - & ++ \\
$A F-5^{5}$ & 1 & - & ++ \\
\hline
\end{tabular}

${ }^{1}$ For gradation of the ciliary reaction see footnote to Table $\mathrm{I}$.

2 Maternal serum was CDF positive.

${ }^{3}$ Mother affected with cystic fibrosis (CF).

${ }^{4}$ Both parents obligate heterozygotes for CF.

${ }^{5}$ Father obligate heterozygote for $\mathrm{CF}$; mother demonstratcd CDF activity in her serum and the medium of phytohemagglutinin-stimulated lymphocytes.

positive CDF response. CDF activity was also observed in the cord sera of the fetuses from whom $A F-2$ and $A F-4$ were obtained. Media from confluent amniotic fluid cells, control or at risk for CF, always produced a ciliary dyskinesia effect before $\operatorname{IgG}$ was added to the samples. The sera from five control pregnant women did not demonstrate CDF activity during a $6 \mathrm{~min}$ bioassay. The amniotic fluid from a pregnancy that resulted in a CF-affected child was CDF negative. 
Table III. Ciliary dyskinesia factor activity of Amicon filtrates and retentates of the culture media of skin fibroblasts derived from patients with cystic fibrosis

\begin{tabular}{|c|c|c|c|c|}
\hline \multirow{3}{*}{ Sample tested } & \multicolumn{4}{|c|}{ Tracheal bioassay } \\
\hline & \multicolumn{2}{|c|}{ Without IgG } & \multicolumn{2}{|c|}{ With IgG } \\
\hline & $3 \mathrm{~min}$ & $6 \mathrm{~min}$ & $3 \min$ & $6 \mathrm{~min}$ \\
\hline Cell-free medium & - & - & ++ & ++ \\
\hline UM-10 filtrate & - & - & ++ & ++ \\
\hline UM-10 retentate & - & - & - & - \\
\hline UM-2 filtrate & - & - & - & \pm \\
\hline UM-2 retentate & - & - & ++ & ++ \\
\hline
\end{tabular}

1 - : no dyskinesia; + : weak dyskinesia ++ : strong dyskinesia; \pm : very weak dyskinesia.

\section{Amicon Filtration}

The UM10 filtrates of media from CF homozygous skin fibroblast cultures demonstrated no CDF activity, but after the addition of $\mathrm{IgG}$ a strongly positive $\mathrm{CDF}$ response was elicited during a 3-min bioassay. The filtrates of UM2 filters, after the addition of $\operatorname{IgG}$, produced a weakly positive CDF effect at $6 \mathrm{~min}$. The retentates of the UM10 filters elicited no CDF activity in the presence or absence of $\operatorname{IgG}$. However, the retentates of the UM2 filters produced a strongly positive $\mathrm{CDF}$ response at $3 \mathrm{~min}$, when $\mathrm{IgG}$ was added. The results of the bioassays performed on the Amicon filtrates and retentates of media obtained from CF skin fibroblast cultures are summarized in Table III.

When a sample of medium from a fibroblast culture from a patient with $\mathrm{CF}$, which demonstrated strong CDF activity with the addition of $\operatorname{lgG}$, was filtered through a UMI0 filter after incubation with $\operatorname{IgG}$, the filtrate was found to be CDF negative. This filtrate again became strongly CDF positive after the addition of $\mathrm{IgG}$. The retentate did not demonstrate CDF activity during a 6 min bioassay. Similar results were obtained after UM10 filtration of CDF-positive long term lymphoid line media derived from CF cultures.

The cell-free media of confluent skin fibroblast cultures derived from normal donors always produced ciliary dyskinesia on rabbit tracheal explants. Filtrates of these media passed through UM10 filters demonstrated strongly positive dyskinesia effect in the absence of human IgG.

\section{Discussion}

This study suggests that cultured skin fibroblasts derived from homozygotes and heterozygotes for CF produce and release into the culture medium a pre-CDF, which is inactive as tested by the rabbit tracheal bioas- say. The pre-CDF is activated by incubation with IgG to produce $\mathrm{CDF}$ as demonstrated by the dyskinetic effect on the ciliary beat of rabbit tracheal explants. The activation of pre-CDF by IgG seems to be a reversible phenomenon which depends on the presence of IgG. This is indicated by the observation that no CDF activity could be demonstrated in the UM10 filtrate or retentate of medium treated previously with $\mathrm{IgG}$ and derived from a $\mathrm{CF}$ skin fibroblast culture, whereas the CDF activity was restored in the filtrate after the addition of IgG. In agreement with this are the findings from the filtration of media derived from CF long term lymphoid lines. The ability to remove $\mathrm{CDF}$ by incubation with anti-IgG, however, implies a loose bond between pre-CDF and $\mathrm{IgG}$, which is broken during UM10 filtration.

The demonstration of a CDF effeect in the cell-free media of one each of the control skin fibroblast cultures and control amniotic fluid cell cultures may indicate that the donors of these cultures are heterozygotes for CF. This is supported by the positive CDF response elicited by the serum of both of the parents and the donor of the CDF-positive control skin fibroblast culture, and the CDF activity demonstrated in the serum of the mother of the CDF-positive amniotic fluid control culture. Although there was a tendency for a stronger positive CDF response in the cell-free media of cultured skin fibroblasts derived from homozygotes than from heterozygotes for $\mathrm{CF}$, no reliable distinction between homozygotes and heterozygotes could be achieved.

The data from the cultured amniotic fluid cells confirm that the CF gene can be detected in vitro by studying the cell-free medium for CDF activity. The fetal donor of $A F^{r}-I$ was at least heterozygous for $\mathrm{CF}$ regardless of the genetic material inherited from the father, because the mother is a homozygote for CF. In view of negative sweat tests of the children represented by $A F-2$ and $A F-4$, these children are probably heterozygotes. Although cord sera in both cases were $\mathrm{CDF}$ positive, we cannot be sure that maternal CDF was not responsible. We intend to test sera of these two children at 6 months of age to confirm their heterozygosity of the CF gene. Although we do not yet know the genetic status of the donors of the cells of the $A F-3$, and $A F-5$, it is likely that they are homozygotes or heterozygotes for CF. Study of the products of the pregnancies of $A F^{-3} 3$ and $A F-5$ after delivery will give us a more accurate estimation of their genetic status with reference to the CF gene.

It seems that study of the cell-free amniotic fluid for 
CDF activity cannot be used for the prenatal detection of the CF gene. However, even if a positive CDF response were elicited by an amniotic fluid at risk, its interpretation would be problematic, inasmuch as maternal CDF-active IgG may cross the placenta and circulate in the fetus.

It is not known if any or all of the three molecular species identified by Bowman et al. [2] by gel filtration in the ciliary activity-inhibiting chromatographic fractions of media from CF skin fibroblast cultures are the ciliary inhibitor (or inhibitors), because ciliary inhibitory activity could not be detected in the three molecular weight species in the oyster system. Since UM10 Amicon filters retain molecules larger than 10,000 molecular weight, the observation that the filtrates through UM10 contained the pre-CDF indicates that the moleecular weight of the pre-CDF is less than 10,000 . In addition, the finding that most of the activity is in the retentate of the UM2 filters, which retain molecules larger than 1,000 molecular weight, suggests that the pre-CDF has a molecular weight between 1,000 and 10,000 .

The nature of the molecule produced by confluent fibroblast cultures derived from normal donors, which produces ciliary dyskinesia, remains unknown. It is unlikely to be identical with the pre-CDF, because no $\operatorname{Ig} \mathrm{G}$ is required for the activation of this molecule (or molecules).

It is difficult to speculate why media from fibroblast cultures derived from homozygotes and heterozygotes for CF inhibit the activity of oyster cilia in the absence of IgG $[2,7]$, whereas our data indicate that addition of IgG is necessary for the demonstration of $\mathrm{CDF}$ activity on rabbit tracheal explants.

The finding that the $\mathrm{CF}$ gene can be detected in cultured amniotic fluid cells may become useful for genetic counseling, although the need for a distinction between homozygous and heterozygous fetuses for $\mathrm{CF}$ is apparent. The greatest potential usefulness of our findings, however, is for the study of the basis genetic defect and the understanding of the pathophysiology of the disease.

\section{Summary}

The cell-free media from skin fibroblasts in growth phase, derived from 13 homozygotes, 1 potential, and 6 obligate heterozygotes for CF, caused ciliary dyskinesia in rabbit tracheal explants in the presence of human IgG. The media from cultured amniotic fluid cells from an obligate carrier of the CF gene fetus and four fetuses at risk for CF also produced ciliary dyskinesia after the addition of IgG. All media from CF homozygous and heterozygous cells were CDF-negative in the absence of human IgG. The culture fluid from 25 of 27 control skin fibroblast cultures and amniotic fluid cells were CDF negative after the addition of IgG. Culture media from confluent skin fibroblasts and amniotic fluid cells, control or CF, always produced ciliary dyskinesia in the absence of IgG. It is suggested that cultured skin fibroblasts and amniotic fluid cells produce a pre-CDF, which is activated by human IgG to produce $\mathrm{CDF}$ active on cilitated rabbit tracheal explants. The molecular weight of the pre-CDF molecule is estimated to be between 1,000 and 10,000 .

\section{Addendum}

Since submission of this paper, the children represented by amniotic fluid cells AF-3 and AF-5 have been delivered. AF-3 is a female with a positive sweat test (96 $\mathrm{mEq} /$ liter chloride) and is therefore affected with CF. No meconium ileus was observed, but the child is growing poorly and has frequent bouts of diarrhea. AF- 5 is a female with a normal sweat test ( $46 \mathrm{mEq} /$ liter chloride). The cord serum was positive for CDF and the child is clinically normal.

\section{References and Notes}

I. BARTMAN, J., WIESMANN, U., AND Blanc, W. A.: Ultrastructure of cultivated fibroblasts in cystic fibrosis of the pancreas. J. Pediat., 76: 340 (1970).

2. Bowman, B. H., Barnett, D. R., Matalon, R., Danes, B. S., AND Bearn, A. G.: Cystic fibrosis: Fractionation of fibroblast media demonstrating ciliary inhibition. Proc. Nat. Acad. Sci. U. S. A., 70: 548 (1973).

3. Conover, J. H., Beratis, N. G., Conod, E. J., Ainbender, E., and Hirschiorn, K.: Studies on ciliary dyskinesia factor in cystic fibrosis. II. Short term leukocyte cultures and long term lymphoid lines. Pediat. Res., 7: 224 (1973).

4. Conover, J. H., Bonforte, R. J., Hathaway, P., Paciuc, S., Conod, E. J., Hrrschrorn, K., ANd Kopel, F. B.: Studies on ciliary dyskinesia factor in cystic fibrosis. I. Bioassay and heterozygote detection in serum. Pediat. Res., 7: 220 (1973).

5. Danes, B. S., and Bearn, A. G.: A genctic cell marker in cystic fibrosis of the pancreas. Lancet, $i: 1061$ (1968).

6. Danes, B. S., and Bearn, A. G.: Cystic fibrosis of the pancreas: A study in cell culture. J. Exp. Med., 129: 775 (1969).

7. DANes, B. S., and Bearn, A. G.: Oyster ciliary inhibition by cystic fibrosis culturc medium. J. Exp. Med., 136: 1313 (1972).

8. Houck, J. C., AND SHARMA, V. K.: Functional failures of "fibrocystic" fibroblasts. Proc. Soc. Exp. Biol. Med., 135: 369 (1970).

9. Kraus, I., Antonowitz, I., Shah, H., Lazarus, H., AND Shwachman, H.: Metachromasia and assay for lysosomal enzymes in skin fibroblasts cultured from patients with cystic fibrosis and controls. Pediatrics, 47: 1010 (1971). 
10. Lieberman, J., and Littenberg, G. D.: Increased kallikrein content of saliva from patients with cystic fibrosis of the pancreas: A theory for the pathogenesis of abnormal secretions. Pediat. Res., 3: 571 (1969).

11. Matalon, R., and Dorfman, A.: Acid mucopolysaccharides in cultured fibroblasts of cystic fibrosis of the pancreas. Biochem. Biophys. Res. Commun., 33: 954 (1968).

12. Pallavicini, J. C., Wiesmann, U., Uhlendorf, W. B., and DI SAN'AGNESE, P. A.: Glycogen content of tissue culture fibroblasts from patients with cystic fibrosis and other heritable disorders. J. Pediat., 77: 280 (1970).

13. RAo, G. J. S., ANd Nadler, H. L.: Deficiency of trypsin-like activity in saliva of patients with cystic fibrosis. J. Pediat., 80: 573 (1972).

14. RAo, G. J. S., Posner, L. A., AND NADler, H. L.: Deficiency of kallikrein activity in plasma of patients with cystic fibrosis. Science, 177: 610 (1972).

15. Russell, S. B., Russell, J. D., and Littheefeld, J. W.: $\beta$-Glucuronidase activity in fibroblasts cultured from persons with and without cystic fibrosis. J. Med. Genet., 8: 441 (1971).

16. Srock, A., Heick, H. M. C., Cress, H., and Logan, W. S.: Abnormal serum factor in patients with cystic fibrosis of the pancreas. Pediat. Res., 1 : 173 (1967).

17. The authors are indebted to Dr. Emanuel Buchwald of the Hospital for Sick Children, Toronto, Canada, for the gener- ous supply of four homozygous and three heterozygous lines used in this study.

18. Grand Island Biological Co., Grand Island, N.Y.

19. Material was kindly supplied to us by Dr. Judith Hall of the Children's Orthopedic Hospital, Seattle, Wash.

20. The authors wish to thank Dr. Garcia-Castro of the University of Pucrto Rico for referring the case to us and the cooperation for the study of this case.

21. Material was kindly supplied by Dr. Bettina Hillman of the Louisiana State University, Shreveport, La.

22. Falcon Plastics, Oxnard, Calif.

23. Meloy Laboratories, Inc., Springfield, Va.

24. Amicon Corporation, Lexington, Mass.

25. E. J. Conod is a United States Public Health Service Predoctoral Trainee in Human Genetics (HD00210). Dr. K. Hirschhorn is a Carcer Scientist of the Hcalth Research Council of the City of New York (I-513).

26. This research was supported in part by grants from the United States Public Health Service (HD02552, and Genetics Center Grant GM19443) and from the National Cystic Fibrosis Research Foundation.

27. Requests for reprints should be addressed to: Nicholas G. Beratrs, M.D., Department of Pediatrics, Division of Medical Genetics, Mount Sinai School of Medicine of the City University of New York, N. Y. 10029 (USA).

28. Accepted for publication August 1, 1973. 